\title{
A MEDIAÇÃo NO CONTEXTO ATUAL: UM CAMINHO PARA O DIÁLOGO TRANSDISCIPLINAR
}

\author{
Washington Souza Coelho ${ }^{1}$ \\ Giovanni Bonato ${ }^{2}$
}

\section{RESUMO}

Este artigo tem como propósito analisar a mediação como forma de solução de conflitos, com argumentos acerca da trasndisciplinaridade do método com outros ramos do conhecimento, tais como a Psicologia, a Filosofia, a Comunicação, a Antropologia, a Sociologia e o Direito. Demostrando a importância da interface da Mediação tais campos do saber. Perfaz-se o contexto histórico sobre a construção do Instituto da Mediação, analisam-se os princípios norteadores e informadores no Brasil e no Mundo. Ressalta-se o fortalecimento dos meios adequados de solução de controvérsias para construção de uma Cultura da Paz como podemos fomentar práticas colaborativas nos conflitos de interesse.

Palavras-chave: Resolução de Conflitos; Mediação; Mudança Cultural; Diálogo Transdisciplinar; Pacificação Social.

\section{MEDIATION IN THE CURRENT CONTEXT: A WAY FOR TRANSDISCIPLINARY DIALOGUE}

\begin{abstract}
The purpose of this article is to analyze mediation as a way of solving conflicts, with arguments about the cross - disciplinarity of the method with other branches of knowledge, such as Psychology, Philosophy, Communication, Anthropology, Sociology and Law. Demonstrating the importance of the interface of Mediation such fields of knowledge. In carrying out such an analysis, the historical context on the construction of the Mediation Institute is analyzed, the guiding principles and informants in Brazil and in the World are analyzed. We emphasize the strengthening of alternative means of dispute settlement for the construction of a Culture of Peace and how society can use collaborative practices in conflicts of interest. Finally, we work with the idea of mediation and transdisciplinary dialogue as a way of working on conflicts of interest.
\end{abstract}

Keywords: Conflict resolution; Mediation; Cultural Change; Transdisciplinary Dialogue; Social Pacification.

\footnotetext{
${ }^{1}$ Mestrando em Direito e Instituições dos Sistemas de Justiça pela Universidade Federal do Maranhão na linha do Mestrado intitulada Meios Alternativos de Solução de Controvérsias, Especialista em Gestão Pública pela Universidade Federal do Maranhão, Especialista em Docência do Ensino Superior pela Faculdade Santa Fé. Instrutor de Mediação e Conciliação e de Oficinas de Parentalidade do Truibunal de Justiça do Estado do Maranhão, Mediador e Conciliador do $1^{\circ}$. Cejusc-Fórum Desembargador Sarney Costa. Mediador Certificado pelo ICFML-Instituto de Certificação e Formação de Mediadores Lusófonos. E-mail:wcoelho20@ hotmail.com ${ }_{2}^{2}$ Possui doutorado em direito processual civil - Università degli Studi di Roma La Sapienza e Universidade de Paris 8 (2007). Maître de conférences na Universidade de Paris Ouest Nanterre La Défense. Ex Professor visitante na Faculdade de Direito da Universidade de São Paulo. Professor Visitante na Universidade Federal do Maranhão, programa de pós-graduação em direito. Tem experiência na área de Direito, com ênfase em Direito Processual Civil, em Arbitragem e em Direito Comparado. Advogado. E-mail: giovannibonato@virgilio.it
} 


\section{INTRODUÇÃO}

A vida em sociedade nos impõe a transposição de barreiras diversas, bem como a tentativa da busca por um convívio harmonioso em sociedade, entretanto verifica-se que o convívio e as relações sociais, são permeadas por conflitos. Sendo assim, o conflito de certa forma, é sempre encarado como algo negativo, basta remeter-se as imagens que nos vem à cabeça quando pensa-se na palavra conflito, quase sempre remonta-se a alguma situação conflituosa e, em número bem resoluto aponta-se para o conflito de forma positiva.

Diante deste cenário, destaca-se que o conflito pode ser analisado de outras formas e não somente na perspectiva negativa, pode ser tratado de modo prospectivo, com o reconhecimento de sua inevitabilidade, tendo em vista, que sua presença é inseparável da vida em sociedade. Ao objetivar resultados de benefícios mútuos possibilita crescimento e desenvolvimento pessoal, uma vez que experiências valiosas poderão ser proporcionadas aos indivíduos inseridos neste contexto, tendo como resultado o fortalecimento e a tão almejada coexistência social.

Denota-se que no imaginário social coletivo o exercício de exigir direitos, está diretamente vinculado ao acionamento do judiciário, ou seja, é análogo ao acesso à Justiça, que acaba por sobrecarregar o Poder Judiciário com novas demandas judiciais e/ou processos, os quais afetam significativamente sua eficiência, acarretando à intitulada crise do Poder Judiciário.

A crise da Justiça brasileira sobrevém da crise do Estado contemporâneo, que advém da dinamicidade das relações, sejam elas comerciais, familiares ou pessoais; não demonstrando plausibilidade na resolução de todo e qualquer conflito existente de forma premente por meio do Poder Judiciário, mas utilizando-se de outros métodos de resolução de conflitos, devendo ficar a cargo do Poder Judiciário em ser a ultima ratio, quando todas as possibilidades de resolução não litigiosa se esgotarem.

O debate acerca do sistema processual brasileiro tem sido veemente, uma vez que, neste contexto, revela-se abarrotado de problemáticas que se metamorfoseiam em entraves a concretização do acesso à justiça, dentre os quais merecem destaque, empecilhos econômicos e a morosidade judiciária. 
Sendo assim, quando da elaboração da Constituição Federal de 1988, esta inseriu no ordenamento jurídico brasileiro um importante princípio para o Estado Democrático de Direito, qual seja: o "Acesso à Justiça", insculpido no inciso XXXV, art. $5^{\circ}$ da Constituição Federal, a garantia de se ter ampliado o acesso ao Poder Judiciário constituiu naquele momento uma grande conquista para a sociedade brasileira.

Neste sentido, verifica-se que os métodos de tratamentos adequados de conflitos têm demonstrado ser uma alternativa eficaz nos tratamentos das demandas, bem como, de ampliação de mecanismos de Acesso à Justiça, entre os quais merecem destaque devido sua eficácia: a mediação, conciliação e arbitragem.

Estes procedimentos permitem uma solução pacífica entre os envolvidos, ao promover transformações e mudança de paradigmas apresentam como resultado principal, o crescimento e desenvolvimento dos indivíduos envolvidos nos conflitos.

Posto que, se verificou não apenas no Brasil recentemente, como em outros países o uso de métodos consensuais de conflitos, notadamente a mediação e a conciliação, que tem servido para a construção de entendimentos que perfazem aos contendores uma maior percepção de uma Ordem Jurídica Justa e reduzindo custos, tempo em contraposição ao método judicante, possibilitando um reestabelecimento das relações e um nível de satisfação maior aos que se encontram em situação de conflito.

Ao longo do ensaio perpassamos pelas origens do instituto da mediação, bem como das bases e princípios norteadores e informadores que estruturam o método. Perfaz-se a noção de transdisciplinaridade e da importância da mediação como prática transdisciplinar e o resultados destas interfaces com outros ramos do saber, tais como a Psicologia, a Filosofia, a Comunicação, a Antropologia, a Sociologia e o Direito.

Por fim, a importância da mediação e da construção de uma Cultura da Paz e da necessidade de uma mudança de mentalidade da sociedade, é possível também visualizar a importância do Mediador como um facilitador do diálogo sendo elemento importante no reestabelecimento dos canais de comunicação entre os envolvidos no conflito.

\section{UM BREVE HISTÓRICO DA MEDIAÇÃO}

As origens históricas do instituto da Mediação perpassam pela possibilidade de dirimir conflitos em sociedade, suas raízes estão imbricadas nas diferentes culturas, ideias, 
tendências e valores de cada época. A existência de disputas nas relações humanas são consequência natural e estão registradas, embora de forma empírica, no seio de várias culturas. Mesmo, que não se possa precisar o local e o momento do aparecimento da mediação, destaca-se que suas origens, segundo alguns estudiosos remontam à China antiga, antes do nascimento de Cristo. Portanto:

os chineses, na antiguidade, influenciados pelas ideias do filósofo Confúcio, já praticavam a mediação como principal meio de solucionar contendas. [....] Para ele, existia uma harmonia natural nas questões humanas que não deveria ser desfeita por procedimentos adversariais ou com ajuda unilateral. [...] (SERPA, 1999, p.67-68)

A utilização da mediação, apesar de bastante antiga e amplamente difundida no oriente, também fez parte de método de condução e de resolução de conflitos de diversas naturezas, tradições religiosas milenares como a cristã, a judaica, a islâmica, dentre outras, utilizaram a mediação. De acordo com Maia; Bianchi; Garcez apud Almeida et al.(2016, p. 44)

As três religiões monoteístas, que servem de base para a cultura ocidental, são um exemplo claro da utilização desses mecanismos. Judaísmo, Islamismo e Cristianismo estão repletos de histórias de mediadores e árbitros. Técnicas de Arbitragem e Mediação são rotineiramente praticadas pelos representantes dessas religiões.

Essa prática, para vários povos tornou-se um meio comum e adequado para a solução dos conflitos, em que no Judaísmo pode ser percebida em passagens "a exemplo do Rei Salomão, [...] já colocando em prática o conceito de solução de disputas por meio do envolvimento de uma terceira parte neutra". (BIANCHI; GARCEZ; MAIA, 2016, p. 44). Ressalta-se que até os dias atuais, os rabinos atuam como mediadores e árbitros para dirimir questões que envolvam assuntos da comunidade judaica. No Cristianismo, a mediação é um ato consolidado tradicionalmente nas comunidades, em que atualmente pastores e padres servem como mediadores ou árbitros. Com o Islamismo:

\footnotetext{
"Maomé, era considerado um grande mediador. Em 622 DC, Maomé mediou, em Medina, acordo entre tribos pagãs, árabes, judeus, cristãos e mulçumanos, o que permitiu a estas diferentes religiões conviver pacificamente na mesma cidade e resultou na primeira constituição escrita: a Constituição de Medina". (BIANCHI; GARCEZ; MAIA, 2016, p. 44).
}

Destacar as origens históricas da mediação, torna-se tarefa quase impossível, tendo em vista, que desde tempos remotos, a mediação é um mecanismo utilizado como caminho para resolução de conflitos desde comunidades primitivas, passando pelas modernas e difundida na contemporaneidade. 
Nos Estados Unidos ao ressurgir nos anos setenta do século XX, passou a ser um procedimento pré-judicial como forma de diminuir o volume de processos no judiciário norte americano, pois a mediação e as demais formas alternativas de resolução de conflitos representaram uma mudança de paradigmas, possibilitando uma maior participação dos membros da sociedade na solução de contendas. Assim, a partir da década de setenta, alguns estudiosos passaram a se ocupar de experiências voltadas à mediação, com adaptações aos ditames modernos.

Tais estudos, em sua versão moderna, possibilitou a prática da mediação de acordo com os preceitos da negociação cooperativa realizados pela Escola de Direito da Universidade de Harvard deram início ao processo teórico da mediação, com estrutura, e técnicas de comunicação. Destaca Vasconcelos apud Fisher; Patton (2015, p. 171)

\begin{abstract}
foram elaborados conceitos e procedimentos, por exemplo, sobre: 1) 'posição' (atitude polarizada e explícita dos disputantes) e 'interesses' (subjacentes e comuns, embora contraditórios ou antagônicos, a serem identificados); 2) técnicas de criação de opções para a satisfação dos interesses identificados; 3) a necessidade de observação dos dados de realidade ou padrões técnicos, éticos, jurídicos ou econômicos; 4) a importância de separar o conflito subjetivo (relação interpessoal) do conflito objetivo (questões concretas)
\end{abstract}

Na América Latina, a mediação começou a ser difundida a partir dos anos 90, aos moldes dos Estados Unidos. O primeiro país a adotar um Programa Nacional de Mediação foi a Argentina quando criou o Decreto $n^{\circ} 1.480 / 1992$ de abrangência nacional, posteriormente foram promulgadas as leis $n^{\circ} 24.573 / 1995$ e 26.589/2010 e o Decreto no 1467/2011. Dessa maneira no contexto atual, "Na prática argentina, notadamente na Gran Buenos Aires, o acesso à via judicial está condicionado à tentativa prévia de soluções do impasse por meio da Mediação" (BIANCHI;GARCEZ;MAIA 2015, p. 47)

A exemplo da Argentina, outros países da América Latina utilizam a Mediação como forma de acesso à justiça, em destaque Chile, Colômbia e Peru em fase de consolidação.

No Brasil destacam Maia, Bianchi, Garcez (2015, p. 47) que em terras nativas "a utilização da Mediação já em 1824, [aconteceu] com a Carta Constitucional do Império, decorrente das Ordenações Filipinas, que instituía a atuação conciliatória do Juiz de Paz, prévia aos processos judiciais (artigos 161 e 162)", a sua atuação era reconhecida como conciliatória semelhante o que faz um mediador.

Com a Proclamação da Independência, mais precisamente na Constituição de 1824, fixou-se verdadeira política pública de solução de conflitos, com a previsão de que 
nenhum processo seria iniciado caso não se registrasse ou se tentasse a reconciliação das partes como constava de seu art. 161. (WATANABE, 2014, p.36).

Nesse período, as questões políticas não eram favoráveis para utilização da solução de conflitos como política pública, enquanto os liberais utilizavam a mediação, valorizando a figura do juiz de paz, os conservadores, impediam a criação e a utilização das formas de conciliação.

Dessa maneira, Watanabe (2014, p. 36) "Proclamada a República, a conciliação, já pouco utilizada, foi inteiramente eliminada de nossa legislação processual, deixando-se de lado a fixação de uma política pública de valorização do consenso, ensaiada por ocasião do Império".

Tal instituto ganhou expressividade, na década de 90, seguindo os outros países da América Latina, com o propósito de solucionar a dificuldade de acesso à justiça, com mecanismos alternativos, garantindo o que reza a Constituição Federal em seu artigo $5^{\circ}$, inciso XXXV.

Portanto, mais de um século depois, com a reformulação do Código de Processo Civil (1994), o entendimento sobre ideia de mediação continuou, para o que se chamou de audiências de conciliação prévia, com o intuito de dirimir as situações conflituosas. Com o Projeto de Lei $n^{\circ} 4.827 / 98$ funcionou como marco inicial para estabelecer a definição de mediação e, expressivamente a partir de 2003, o debate foi mais amplo acerca da utilização de meios alternativos para solução de conflitos.

No ano de 2009, com a apresentação do projeto do novo CPC:

pode-se identificar a preocupação do legislador com os institutos da conciliação e da mediação. Ocupa-se, especificamente, da regulamentação da mediação no curso do processo judicial. Isso não exclui, contudo, a mediação prévia ou mesmo a possibilidade de utilização de outros meios de solução de conflitos ( BIANCHI; GARCEZ; MAIA, 2017, p. 48)

Os princípios informadores da conciliação e da mediação foram resguardados e o CPC vigente, cita a conciliação em vários dispositivos, sendo reconhecida com a Resolução no 125/2010, que trata sobre a Política Judiciária Nacional, levando em consideração os princípios da independência, neutralidade, autonomia da vontade, confidencialidade, oralidade e informalidade.

Destaca Watanabe (2014, p. 37) os principais pontos da Resolução n ${ }^{\circ}$ 125/2010:

a) A mudança de paradigma dos serviços judiciários, abrangendo também os mecanismos consensuais de solução de conflitos. Incluiu-se, portanto, nos serviços judiciários, além da solução jurisdicional, a possibilidade da utilização de outros mecanismos, como a mediação e conciliação (art. $1^{\circ}$, caput e parágrafo único). 
b) A exigência de que esses mecanismos sejam desenvolvidos com qualidade, com a capacitação adequada de mediadores e conciliadores;

c) A centralização dos serviços de conciliação em centros ou centrais, assegurando-se o seu permanente aperfeiçoamento através de dados estatísticos.

Com a propositura da Resolução 125/2010 surgiram várias iniciativas para disseminação da Mediação pelo Brasil, com criação de centros de Mediação do Judiciário nos tribunais estaduais e tanto a conciliação quanto a mediação passaram de meios alternativos de solução de conflitos para meios adequados de solução de controvérsias (KOURY, 2016, p.134).

Vários projetos foram adotados com o propósito de sensibilizar juízes e a sociedade judiciária sobre a importância de incentivar a busca da autocomposição, quando possível, pelas partes. Dentre, tais iniciativas tem-se as instituições de ensino superior que passaram a oferecer disciplinas sobre Mediação, a OAB também foi grande fomentadora para legitimar o instituto da Mediação, diversas seccionais passaram a ter comissões temáticas compromissadas com o desenvolvimento da Mediação, "em março de 2015, o Conselho Federal da Ordem dos Advogados do Brasil, por meio de seu Colégio de Presidentes, instituiu o Pacto Nacional da Advocacia pelos Métodos Extrajudiciais de Solução de Conflitos". (BIANCHI; GARCEZ; MAIA; 2017, p. 49).

\title{
2. O ACESSO À JUSTIÇA COMO DIREITO FUNDAMENTAL E A REGULAMENTAÇÃO DAS ATIVIDADES DE MEDIAÇÃO
}

Desde o século passado, o acesso à justiça como direito humano e fundamental está pautado em três iniciativas ou efetivas de acesso, segundo Vasconcelos (2015, p. 80):

\begin{abstract}
a primeira intentando frustrar o obstáculo econômico na fruição dos direitos humanos, o que se viabiliza pela assistência judiciária gratuita para as pessoas de baixa renda. A segunda tendo por finalidade combater o obstáculo organizacional, possibilitando a defesa de interesses de grupo, difusos ou coletivos, por meio das ações populares ou coletivas. Já a terceira onda, objetivando combater o obstáculo processual de acesso à justiça, mediante a expansão e o reconhecimento dos direitos humanos, por todos os meios que reduzam o congestionamento crônico dos sistemas judiciários internos da maioria dos Estados.
\end{abstract}

A busca por superar a restrição da abrangência do significante justiça à categoria de sinônimo de Judiciário, acarretou em extrapolar a limitação do acesso à justiça como uma garantia meramente formal de ingresso no sistema judicial de administração de conflitos. 
Nesta perspectiva, faz-se necessário ressaltar que o conceito de acesso à justiça sofreu algumas alterações que foram adotadas, especialmente, após a Constituição de 1988 e após Emenda Constitucional 45 (EC 45/2004), com o propósito de entender esse direito tanto de forma quantitativa, quanto qualitativamente.

Entende-se que, “[...] de nada adianta um Poder Judiciário que não seja capaz de conferir eficácia aos direitos fundamentais e, vice-versa, de nada adianta um elenco de direitos fundamentais se o Poder Judiciário não é capaz de garanti-los, de implementá-los". (CAMPILONGO, 2000, p. 101).

Busca-se uma efetividade prática e real da prestação jurisdicional, pois a denegação da justiça pelos tribunais torna-se desproporcional, à medida que nega um dispositivo constitucional assegurado pelo Estado, em seu art. $5^{\circ}$, inciso XXXV e despropositada na medida em que implica a desconsideração da relevância universal fundamental de direitos humanos, proclamada pela Declaração Universal dos Direitos Humanos, que estabelece: “Art. $8^{\circ}$. Todo homem tem direito de receber dos Tribunais nacionais competentes remédio efetivo para os atos que violem os direitos fundamentais que lhe sejam reconhecidos pela Constituição ou pela lei”.

A garantia formal de acesso ao Judiciário é um direito humano fundamental, uma exigência que se explica como fundamental a todo e qualquer sistema jurídico que tem compromisso com a efetividade. Assim, Grinover apud Vasconcelos (2015, p. 80) reitera que:

\begin{abstract}
no processo civil, o desenvolvimento de uma 'justiça conciliativa', a partir de três fundamentos: o fundamento funcional, para enfrentar a inacessibilidade, a morosidade e o custo do Judiciário, demandando a adoção de uma política judiciária de mediação e conciliação; o fundamento social, consistente na função de pacificação social, que, via de regra, não é alcançada pela sentença, que se limita a ditar, autoritariamente, a regra para o caso concreto, resumindo-se a solucionar a parcela de lide levada a juízo, sem possibilidade de pacificar a lide sociológica; e o fundamento político, consistente na participação popular na administração da justiça, representando ela, ao mesmo tempo, instrumento de controle, configurando meio de intervenção popular direta pelos canais institucionais de conciliação e mediação. [grifo meu]
\end{abstract}

A justiça conciliativa em destaque pelos autores, passa por três obstáculos como mencionados, primeiramente, o fundamento econômico ou funcional trata-se " [...] da pobreza de muitas pessoas que, por motivos econômicos, nenhum ou pouco acesso tem à informação e à representação adequada"(CAPPELLETTI, 1994, p. 84).

O fundamento econômico está vinculado a diversos fatores, dentre estes destacase a formalidade do sistema jurídico que acaba por procrastinar o tempo de duração dos processos, denotando aumento dos custos para as partes que estão em litígio. Portanto, há de 
se notar, efeitos negativos que entravam, os requisitos da informação e da representação adequada, prejudicando o acesso à justiça por questões financeiras.

O entrave econômico gera desigualdades causando uma marginalização no sistema judiciário, dessa maneira, os meios alternativos de solução de conflitos tem o condão de conceder "o acesso à justiça, como direito fundamental, corresponde ao direito que cada cidadão tem individualmente ao exercício da função jurisdicional sobre determinada pretensão de direito material, sobre o mérito do seu pedido". (GRECO, 2003, p. 64).

Neste quadro de possibilidades de soluções práticas para os problemas de acesso à justiça, atualmente, o Estado utiliza medidas com o propósito de efetivação da mediação como uma das vias de acesso à justiça brasileira, estas foram instituídas pelo Conselho Nacional de Justiça (CNJ), e as outras levando em consideração o desenvolvimento de políticas públicas sobrevindas do Legislativo, tem-se o novo CPC (Lei no 13.105/2015) e a Lei de Mediação (Lei $n^{\circ}$ 13.140/2015). Para tanto, enfatiza-se que a barreira da questão econômica, passa a ser dirimida, diante do que se concebe com as considerações do CNJ pois “convergem para a busca da efetivação do acesso integral à justiça, na medida em que são concebidas a partir de pressupostos carregados de pretensões incontestavelmente democratizantes" (GORETTI, 2017, p. 191)

A crescente complexidade social e a gama de atribuições do Estado aumenta a cada dia e passou a exigir-se maior dinamicidade para tentar atender as demandas, portanto, o Estado deveria adotar uma conduta positiva com a obrigação de prestar bons serviços aos seus jurisdicionados para de fato garantir direitos fundamentais, que são amparados pelo Estado Democrático de Direito. Assim, Gomes Neto (2005, p. 57) ressalta que, "como serviço de natureza pública, é direito dos consumidores (jurisdicionados) que lhes seja prestado de modo eficiente, rápido e efetivo (numa clara dimensão teleológica de origem valorativa)".

Dessa maneira, destaca-se em análise a segunda problemática ou fundamento social, seria a representação dos interesses difusos, conhecidos como interesses coletivos ou de grupos, diversos daqueles dos pobres. "Esta segunda onda de reformas forçou a reflexão sobre noções tradicionais muito básicas do processo civil e sobre o papel dos tribunais". (CAPPELLETTI; GARTH, 2002, p. 49)

A contextualização socioeconômica que ensejou a valorização de direitos difusos e coletivos, destacou-se por rupturas paradigmáticas que denotavam um longo processo de transição das questões econômicas inter-individuais, para interesses mais complexos, que são 
determinantes em uma sociedade massificada por diversidade de produção, distribuição e consumo de bens e serviços.

Os direitos e os interesses difusos e coletivos merecem atenção de forma particularizada das considerações que os norteiam, tendo em vista que estão na esteira de lutas e conquistas que motivaram o surgimento de direitos sociais novos, dentre esses os proteção de grupos que por longos séculos foram marginalizados, a exemplo de, mulheres, crianças, deficientes, idosos e minorias étnico/raciais.

A terceira problemática ou fundamento político centra seus esforços nos ditames processuais, pois de acordo com Cappelletti; Garth (2002, p. 67) "o progresso na obtenção de reformas da assistência jurídica e da busca de mecanismos para a representação de interesses 'públicos' é essencial para proporcionar um significativo acesso à justiça”

A terceira onda como também é conhecida, tem suas limitações e deve estar pautada nas desconstruções das inadequações de procedimentos processuais, pois, a depender da área ou espécie de litígio, a forma tradicional não é a melhor alternativa para a reivindicação de direitos. Dessa maneira, essa,

reforma inclui a advocacia, judicial ou extrajudicial, seja por meio de advogados particulares ou públicos, mas vai além. Ela centra sua atenção no conjunto geral de instituições e mecanismos, pessoas e procedimentos utilizados para processar e mesmo prevenir disputas nas sociedades modernas. (CAPPELLETTI; GARTH, 2002, p. 67-68)

Assim, os conflitos que chegam ao judiciário exigem um tratamento diferencial uma celeridade pontual e equilibrada com apreciação detalhada, pois com esses mecanismos alternativos de acesso à justiça (arbitragem, conciliação e mediação), segundo Reichelt (2017, p. 245)

A compreensão do conteúdo do direito fundamental à inafastabilidade do controle
jurisdicional como manifestação de atividade desenvolvida no âmbito da separação
de poderes e funções do Estado é vista como uma fórmula que não exclui a
possibilidade de existência de outras ferramentas igualmente comprometidas com a
preocupação de solucionar conflitos.

Dessa maneira, funcionam como estratégias ou possibilidades para dirimir tais controvérsias sociais e interindividuais, denotando que o próprio modelo de conflitos de jurisdição precisa ser repensado. No contexto atual, o modelo tradicional é posto em discussão:

e desse encontro de razões resulta a construção de um direito fundamental que se enquadra dentre aqueles relativos à organização e ao procedimento, o qual é dotado de considerável sofisticação se comparado com outras ferramentas predispostas no ordenamento jurídico pátrio. (Reichelt, 2017, 246) 
O modelo 'multiportas"3 de acesso à justiça, passa a ser uma adoção de prestação positiva e garantia do direito fundamental de liberdade, amparado pelo novo CPC, respeitando a autodeterminação das partes, agora sem a intermediação de um terceiro entre elas, empregando uma formulação respaldada em princípios com vistas a produção de um resultado, por meio de regras a serem observadas por determinados sujeitos ao exercer a função do Estado em dizer o Direito.

\section{PRINCÍPIOS INFORMADORES DA MEDIAÇÃO NO BRASIL E NO MUNDO}

A Mediação é tida como um procedimento não adversarial de resolução de conflitos, em que as partes de forma voluntária, consensual e em conjunto procuram uma solução para dirimir um conflito, com o auxílio de um terceiro que age de forma neutra.

O terceiro ou mediador representa o facilitador na negociação entre as partes, ou seja, além da imparcialidade, o mediador deve utilizar com propriedade os procedimentos e as técnicas adotadas, agindo com competência na condução da resolução do conflito, outra característica do mediador é o comprometimento com os interesses reais e necessidades das partes, buscando soluções isonômicas.

O artigo 166 do CPC, destaca que a conciliação e a mediação estão pautados em tais princípios, moldando o mediador sob uma ética, que mantêm imparcialidade, melhor forma de tratamento do conflito, informalidade, na qual as partes tem oportunidade de debater os problemas que lhes envolvem, buscando a melhor solução para eles, dever de sigilo, ou seja, a este profissional cabe esferas principiológicas que contribuem necessariamente para a resolução de conflitos da melhor maneira possível. Tais princípios informais estão lastrados em um princípio maior o da dignidade humana. Assim,

Destacam-se como suas diretrizes essenciais o princípio da dignidade humana - já que um dos pilares dos meios consensuais é o reconhecimento do poder de decisão das partes (com liberdade e autodeterminação) -, a informalidade, a participação de terceiro imparcial e a não competitividade. Tartuce (2015, p. 189)

\footnotetext{
${ }^{3}$ Há de se pensar novos modos de dimensionamento destes conflitos que ultrapassem os limites do que vem sendo implementado pela Resolução do CNJ n 125/2010, especialmente quando o Novo Código de Processo Civil (Lei no 13.015/2015) procura instituir um modelo multiportas (multi-door system) em consonância com outros sistemas estrangeiros que se valem de soluções integradas de conflitos mais consentâneas com as mudanças sociais das litigiosidades. Analisar esta tendência legislativa é o propósito deste breve ensaio. Ao se analisar o disposto no art. $3^{\circ}$ do Novo CPC, percebe-se notória tendência de se estruturar um modelo multiportas que adote a solução jurisdicional tradicional agregada à absorção de outros meios. (ZANETI JR.; TRÍCIA,2016, p.269)
} 
Nesse contexto, os princípios informadores passam a fazer parte da dinâmica do instituto da mediação, "foram delimitados no art. 166 do CPC/2015. São eles: independência, imparcialidade, autonomia da vontade, confidencialidade, decisão informada, oralidade e informalidade" (GORETTI, 2017, p. 243)

a) Informalidade e independência: Com a participação de um mediador/conciliador estabelecem-se regras e dinâmicas da autocomposição. A mediação pela informalidade facilita o diálogo entre as partes, sem possuir regras fixas, portanto, a flexibilidade é uma especificidade deste princípio. "O que se propõe é certa flexibilização nos atos delineadores da mediação/conciliação. Pretende, o legislador, atingir, com a informalidade, premissa tratada pelas mais modernas legislações processuais: celeridade" (SPENGLER, 2017, p. 149)

Vale destacar, que embora não exista uma exigência formal para a condução da técnica em mediação, a esta é aplicável as regras da confidencialidade ao procedimento, não devendo ser vista como uma contradição, pois a informalidade favorece a cooperação e a adequação de parâmetros que evidenciem o acordo com as necessidades de preparo e cautela disponíveis pelo mediador. Com o princípio da independência, destaca-se que esta

vai além [...], uma vez que diz respeito também à hipótese de garantir autonomia e liberdade ao conciliador/mediador para que realize a sessão conforme seus conhecimentos e práticas (desde que lícitos), livre de pressão interna e/ou externa, seja quanto aos resultados, seja quanto à condição do procedimento. (SPENGLER, 2017, p. 147).

Dessa forma, a privacidade e a informalidade possibilitam as partes ficarem tranquilas e descontraídas, possibilitando melhores resultados em âmbito consensual. A informalidade denota uma logicidade com pautas viáveis que se valem de técnicas na comunicação e na interação das partes com resultados satisfatórios para os envolvidos.

Tratando-se de mecanismo que busca o restabelecimento da comunicação, muitas vezes o encaminhamento da controvérsia deverá ser conduzido segundo as situações pessoais dos envolvidos e as condições concretas de sua relação. Em geral, muitas são as oportunidades de atuação do mediador junto às partes, e cada encontro pode ser conduzido de forma diversa. Geralmente, as sessões de mediação são várias e não há regras fixas de condução do procedimento. (TARTUCE, 2017, p. 197)

Os métodos alternativos são mais amigáveis e flexíveis, lembrando que as partes buscam decidir conforme suas reais necessidades, tendo em vista que a informalidade se une a independência para uma atuação do mediador com autonomia e liberdade. 
b) Imparcialidade: representa à diretriz e, é crucial tanto nos meios

adjudicatórios quanto nos consensuais, é considerada fator determinante para o reconhecimento da credibilidade do mediador, pois sua presença valida a atuação deste estranho que intervém na lide.

O princípio da imparcialidade decorre da impossibilidade de o mediador/conciliador privilegiar um dos litigantes em detrimentos dos demais, como também seria dever de qualquer julgador, enquanto presidente de uma seção. Por ser imparcial, o mediador/conciliador não se posiciona a favor de nenhum dos lados, privilegiando o diálogo e as escolhas pessoais de cada um. (SPENGLER, 2017, p. 147)

O mediador deve ser imparcial, ou seja, completamente alheio aos interesses em conflito, dessa forma, não pode ter vínculos pessoais com as partes, para que haja o sucesso e a certeza de sua independência. A Resolução 125/2010 do CNJ (apud TARTUCE, 2017, p. 206)

esta é o dever de agir com ausência de favoritismo, preferência ou preconceito, assegurando que valores e conceitos pessoais não interfiram no resultado do trabalho, compreendendo a realidade dos envolvidos no conflito e jamais aceitando qualquer espécie de favor ou presente.

O comportamento imparcial destaca igualdade de tratamento, pois o mediador não pode se manifestar ou expor juízo de valor, tendo em vista que o propósito é garantir às partes paridade de oportunidade de apresentar suas razões, atuar com transparência e compromisso faz com que o mediador tenha comprometimento ético e consiga a confiança das partes em litígio.

c) Autonomia da vontade: conhecida também como autodeterminação denota em deliberação voluntária e as partes devem escolher a consensualidade. O mediador deve atuar com liberdade e observância dos preceitos legais e as partes devem desejar participar de uma mediação ou conciliação. A mediação permite que as partes protagonizem uma saída consensual, valorizando sua percepção e o senso de justiça. Dessa maneira, Spengler (2017, p. 173) destaca que:

\footnotetext{
“a mediação no Brasil é voluntária, ou seja, os conflitantes têm autonomia para aceitá-la ou rejeitá-la. Não obstante opiniões diversas que entendem a necessidade de fazer do procedimento mediativo uma obrigação, o que acarretaria na informação e conhecimento a respeito da mediação e, quem sabe, na final concordância em participar do seu procedimento, o fato é que impor a mediação fere os princípios básicos da liberdade, da autonomia e da responsabilidade".
}

O indivíduo ao ser protagonista e responsável em suas decisões estreitadas no instituto da mediação, estabelece como característica principal a conduta ética e a dignidade humana. Assim, a dignidade como fator determinante dos direitos fundamentais valoriza o 
indivíduo com cidadão, respeitando a sua integridade física e psíquica, na busca de resolução dos seus conflitos pela mediação.

[...] a dignidade é um valor espiritual e moral inerente à pessoa, que se manifesta singularmente na autodeterminação consciente e responsável pela própria vida e que traz consigo a pretensão ao respeito por parte das demais pessoas, constituindo um mínimo invulnerável que todo estatuto jurídico deve assegurar, de modo que, somente excepcionalmente, possam ser feitas limitações ao exercício dos direitos fundamentais, mas sempre sem menosprezar a necessária estima que merecem todas as pessoas enquanto seres humanos. (MORAES, apud TARTUCE 2017, p. 191).

Os mediadores, através da autonomia da vontade proporcionam aos envolvidos a oportunidade de aprender a lidar com os seus conflitos pessoais e de convivência social, pois possibilita as partes a promoção do exercício da autodeterminação.

d) Oralidade: De cunho informal, a mediação se desenvolve por meio de conversa e/ou negociação entre as partes, utiliza-se da iniciativa verbal, com questionamentos e afirmações, meios de expressão em que viabilizam um espaço de comunicação entre as partes, para que estes busquem saídas para seus conflitos, as técnicas de provocação são variadas, pois provocam reflexão e elaboração de perguntas. Ressalta, Cesar Peluso (apud TARTUCE, 2016, p. 199) "a maior integração das partes na solução dos conflitos é guiada, sobretudo, pelo princípio da oralidade, e "não teria sentido se não lhes fosse dada a oportunidade de engendrar ou conceber sua própria decisão".

O princípio da Oralidade sustenta o envolvimento das partes com a partilha de um espaço participativo, objetivando o consensualismo, permitindo condições para um cenário colaborativo. Portanto, a oralidade permite reciprocidade diante da técnica aplicada, integrando as partes a compor o cumprimento da resolução de conflitos de maneira espontânea e dispensando a formalização do acordo de forma escrita.

e) Busca do consenso, cooperação e não competitividade: a mediação promove conversações úteis para as partes, o mediador deve contribuir com condições para que os envolvidos possam atuar em uma situação cooperativa, aumentando as chances de alcançar os objetivos almejados.

Assim, Grinover destaca (apud TARTUCE, 2016, p. 207) "que a participação dos sujeitos no processo, em colaboração com o juiz, deve implicar colaboração para o exercício da jurisdição com o intuito de uma prestação jurisdicional de boa qualidade".

Ao atuar como intermediário facilitador, o mediador deve promover estratégias satisfatórias e produtivas. Ao atuar como facilitador, o mediador deve buscar uma negociação que avance, rumo ao consenso, pois este é indispensável a autocomposição, que embora não 
termine em acordo, mas que possa permitir aos envolvidos no conflito entender que a técnica atinge sucesso quando as partes saem satisfeitas.

f) Boa-fé e confidencialidade: Por se tratar de mecanismos consensuais a boa-fé é essencial para que se atinja uma solução em conjunto. A boa-fé parte do pressuposto da existência de sentimento e convencimento íntimo, vinculados à honestidade, lealdade e justiça do próprio comportamento para um desenvolvimento da dinâmica de maneira eficiente.

A boa-fé se une a confidencialidade, para estimular comprometimento dos envolvidos, tendo em vista, que o mediador age para que as partes possam falar abertamente sem prejuízo da atuação da boa-fé, pois as partes devem se sentir à vontade para narrar informações de foro íntimo e privado com a garantia de que tudo será confidencial.

A confidencialidade é o instrumento apto a conferir um elevado grau de compartilhamento para que as pessoas se sintam 'à vontade para revelar informações íntimas, sensíveis e muitas vezes estratégicas’ que certamente não exteriorizam em um procedimento pautado pela publicidade. (TARTUCE, 2016, p. 211).

Para as diretrizes do acordo se propicia inúmeras saídas produtivas para os conflitos, em que as partes destacam o que querem deixar ou não em confidencial. Ressalta, Tartuce (2016, p. 213)

A Resolução 125 do CNJ enfoca a confidencialidade como dever de manter sigilo sobre as informações obtidas na sessão, salvo autorização expressa das partes, violação à ordem pública ou às leis vigentes, não podendo o conciliador/mediador ser testemunha do caso nem atuar como advogado dos envolvidos em qualquer hipótese (Anexo III, art. $1^{\circ}$, I)

g) Isonomia: Trata-se de igualdade de oportunidades de manifestação das partes durante a aplicação do procedimento, a participação do mediador imparcial se dá em informar as partes como será a técnica desenvolvida, para que não haja dúvidas com relação à técnica e a comunicação.

O mediador deve indagar as partes se conhecem dados relevantes para possíveis soluções construídas de forma consensual, com interesses comuns, após tais perguntas, este deve utilizar a técnica mais adequada para a solução do conflito. Pois, "O mediador/conciliador pode encarar dois tipos de problemas: de percepção [...]; e da existência de relação extremamente assimétrica [...]” (MOORE, apud TARTUCE, 2016, p. 216).

Destaca-se que os problemas que causam divergências não decorrem única e exclusivamente das questões econômicas, mas, trata-se da legitimidade da argumentação, da formulação de ideias criativas, princípios morais e outras divergências que possam existir. 
Os princípios em destaque direcionam as relações jurídicas, consolidando um processo de mediação eficaz, em que os envolvidos estabelecem um diálogo direto, com a participação de um mediador que é responsável por uma comunicação transformativa.

\title{
4. MEDIAÇÃO E O DIÁLOGO TRANSDISCIPLINAR
}

O instituto da mediação, como viu-se no decorrer do ensaio, obteve grande relevância no Sistema Jurídico brasileiro, o que fez com que profissionais de outros campos do conhecimento se interessassem em realizar uma interface com esta importante técnica. Antes de adentrar-se na importância do diálogo entre a mediação e outros campos saber, fazse necessário saber o conceito de transdisciplinaridade. Dessa forma, (ROSENBLATT, 2017, p. 141):

\begin{abstract}
A transdisciplinaridade por sua vez, é o passo dado no sentido de uma mistura, de um atravessamento, de um uso complexo de diversas disciplinas, sem que por isso se forma uma nova disciplina. No sentido da transdisciplinaridade, encontra-se tanto estudo que se utilizam de instrumental teórico, conceitual e empírico de diversas disciplinas, quanto práticas transdisciplinares, que mesclam diversos saberes em seus procedimentos de ação.
\end{abstract}

No cerne da palavra transdisciplinaridade, expressa pelo prefixo trans, pulsa o que está entre, através e além do que se observa, se pensa, cria, sabe-se e faz. O prefixo trans remete para três pilares da transdisciplinaridade, ou seja: a complexidade, a lógica do terceiro incluído e os níveis de Realidade. Neste sentido, o que caracteriza a transdisciplinaridade é o foco no objeto real, dotado de complexidade, e, não mais no objeto forjado de uma disciplina. Ela busca se valer dos saberes como instrumentais para a compreensão da realidade, portanto, a ciência deve "se valer de um plano de referência, que simplifica a natureza complexa dos particulares estudados, para poder, justamente, ser estendida para outros particulares que não foram objeto do estudo" (DELEUZE; GUATARRI apud ROSENBLATT, 2017, p. 136)

Sendo assim, visualiza-se a importância da mediação como saber transdisciplinar, pois o instituto ora estudado, por si só apresenta-se como uma prática inclusiva e ao longo do seu desenvolvimento, absorveu influências, técnicas e conceitos de variados campos do conhecimento. Dessa forma, Rosenblatt (2017, p. 141) destaca que:

a mudança de paradigma aqui tratada deu origem a saberes multidisciplinares, como a saúde coletiva, que necessita em sua formação de diversas disciplinas, embora sua ênfase concentre seu foco em algumas áreas, como o sanitarismo, a epidemiologia e a gestão em saúde. 
Diversas áreas do conhecimento emprestam para a mediação uma possibilidade multiprofissional, transdisciplinar, e mais ainda multidisciplinar, pois mescla conjunto de saberes. A Mediação como meio comunicacional, para aproximação das pessoas, utiliza-se de teorias da Comunicação, sendo que o estudo desta disciplina possibilita que o mediador possa compreender a dinâmica do conflito, por meio da fala dos mediandos, da linguagem corporal destes, a forma como se comunicam uns com os outros e, por fim trata da necessidade de trabalhar os canais de comunicação para que estejam abertos e que não haja ruídos na comunicação entre os contendores do conflito.

A Psicologia funciona como um outro campo do conhecimento que auxilia muito na prática da Mediação, possibilita a compreensão da importância das emoções e dos afetos.

Abre-se a possibilidade para que os mediandos deixem de ver o conflito como algo externo, provocado exclusivamente pelo outro, e compreender que sua manutenção é alimentada pela maneira como as ações de ambos são recebidas, sentidas, interpretadas e respondidas. (ROSENBLATT, 2017, p. 143)

No âmbito do conflito, permite que as partes sejam acolhidas e trabalhadas de modo que não se tenha nenhum obstáculo ao diálogo. Neste sentido, a Psicologia é extremamente importante para o desenvolvimento da Mediação e para o trabalho do mediador, pois através desta é possível perceber as motivações, os desejos, a passionalidade e os afetos intricados nas posições, argumentações e atitudes dos mediandos.

A partir da compreensão destes aspectos é possível que se possa despertar uma reflexão, fazendo com que as partes deixem de ver o conflito como algo externo, provocado pela maneira como as ações de ambas são recebidas, sentidas, interpretadas e respondidas.

Logo, a mediação alicerçada com os conhecimentos da Psicologia proporciona uma reflexão quanto à prática e oportuniza aos mediandos uma prática de diálogo interno.

A filosofia, a antropologia e a sociologia também são importantes áreas para que sejam verificados elementos fundamentais na prática da mediação, tais como, a noção de ética que permeia o procedimento, é possível ainda, que se visualize a percepção do ser humano como um ser social, integrante de variados grupos. Ressalta (ROSENBLATT, 2017, p. 143)

Na filosofia, mediadores buscam a sustentação de uma noção de ética que permeie consistentemente o processo de mediação. É fundamental que a Mediação seja guiada pela ética e não por uma moral específica, previamente determinada por algum valor do mediador. 
Através destes conhecimentos transdisciplinares é possível fazer com que se possa viabilizar a construção e manutenção das conexões dos mediandos com os diferentes grupos aos quais estes interagem.

Por fim, cita-se o Direito, que contribui com a noção de acesso à justiça, pois é através deste, que os mediandos potencializam tal concepção em sua acepção contemporânea de ordem jurídica justa. A mediação juntamente com o Direito, viabiliza que os mediandos protagonizem a solução de seus conflitos, conferindo maior legitimidade à decisões tomadas de acordo com suas necessidades e possibilidades.

Com a aplicação transdisciplinar a "Mediação convida os mediandos a protagonizarem a solução de seus conflitos, conferindo legitimidade às decisões tomadas de acordo com suas necessidades e possibilidades, o que lhes garante maior efetividade e satisfação”. (ROSENBLATT, 2017, p. 144)

Deste modo, as diferentes disciplinas contribuem significativamente com a Mediação, pois auxiliam tanto os mediadores quanto aos mediandos a construírem de forma clara uma geração de informações necessárias ao processo de reflexão e à tomada de decisões, portanto a Mediação se fortalece e ganha impulsão com as contribuições das diversas áreas do saber.

\section{CONSIDERAÇÕES FINAIS}

Ao longo do ensaio observou-se que os meios de solução de conflitos, em especial a Mediação, foi consolidada de forma inovadora pelos ordenamentos pátrios a exemplo da Resolução 125/2010 do CNJ, da Lei de Mediação e do Novo CPC, com o objetivo de realizar uma transformação na mentalidade da sociedade e dos operadores do Direito, com necessidade cotidianamente, de uma mudança cultural do paradigma adversarial para o paradigma do consenso e do diálogo.

Sabe-se que as mudanças são frutos de um processo e que existe a necessidade de uma maturação com o que é novo, assim como ocorrera com outras legislações, o Novo Código de Processo Civil e a Lei de Mediação trouxeram mudanças substanciais para o mundo fático, que tem sido maturadas e tem desconstruído de certa forma padrões até então estabelecidos, um deles de que para resolver um conflito, tenho que falar mais alto ou possuir uma postura mais adversarial, dura ou necessariamente tenho que ser "bom de briga". 
Este tipo de comportamento a cada dia perde espaço, sobretudo porque há uma exigência de uma nova postura por parte das pessoas, pois vive-se em novo momento, onde é cada vez mais premente a mudança de um modelo litigioso no mundo jurídico para um modelo dialogado, onde se distancia cada vez mais, do modelo judicante e nos aproxima da possibilidade de escolha por um meio multiportas para a resolução dos conflitos.

Existe a necessidade ainda, da busca de soluções que possam trazer uma maior efetividade na solução dos conflitos, pois a litigiosidade há muito, já demonstrou que não é o melhor caminho e que o Estado não é o ente mais apropriado para dizer o Direito.

Sendo assim, as legislações recentes que tratam sobre o assunto, evidenciam um momento crucial de alterações no ordenamento pátrio, reforçando o uso de meios dialogados para o tratamento dos conflitos, bem como o fortalecimento de institutos como a Mediação e a Conciliação. Portanto, os métodos adequados de resolução de conflito, notadamente, despontam como ferramentas de atuação dos cidadãos no controle político-civil, ao oportunizar a edificação de acordos através da comunicação, proporcionam, também, a prática da cidadania, uma vez que permitem a participação ativa do cidadão na vida política, consequentemente, materializando os preceitos democráticos, aprimorando o acesso à Justiça, a uma ordem jurídica justa, concreta, oportuna e apropriada aos propósitos dos envolvidos, corporificando múltiplos mandamentos constitucionais, como os princípios da dignidade da pessoa humana, da igualdade, da liberdade e solidariedade.

Por fim, verifica-se a importância de uma postura colaborativa por parte da sociedade, o que é essencial em uma sociedade cada vez mais competitiva, hoje se exige um conhecimento transdisciplinar em todas as áreas do conhecimento, é necessário que todos profissionais possuam habilidades comunicacionais e que facilitem o diálogo entre os contendores dos conflitos.

A Mediação hoje proporciona o tratamento do conflito de forma mais profunda e visa o reestabelecimento dos laços entre os contendores e não apenas a solução do problema, pois tal postura irá fazer com que haja um sentimento de satisfação muito maior por parte dos contendores do conflito, bem como, um sentimento de efetividade e celeridade muito mais real do que o modelo judicante adotado atualmente por grande parcela da população.

\section{REFERÊNCIAS}


ALMEIDA, Tania. Mediação de Conflitos: para iniciantes, praticantes e docentes / Coordenadoras Tania Almeida, Samantha Pelajo e Eva Jonathan - Salvador. Ed. JusPodvm, 2016.

ANDRIGHI, Fátima Nancy. A mediação, um propósito de transcendência para o ensino. Aspectos Atuais sobre a mediação e outros métodos extra e judiciais de resolução de conflitos/ Adolfo Braga Neto, Lilia Maia de Morais Sales. Rio de Janeiro: GZ Ed. 2012.

ANDRIGHI, Fátima Nancy. A mediação, um propósito de transcendência para o ensino. Aspectos Atuais sobre a mediação e outros métodos extra e judiciais de resolução de conflitos/ Adolfo Braga Neto, Lilia Maia de Morais Sales. Rio de Janeiro: GZ Ed. 2012.

AZEVEDO. André Gomma (Org.). Manual de mediação judicial. Brasília/DF:

BACELAR, Roberto Portugal. Mediação e arbitragem / Roberto Portugal Bacelar. - São Paulo: Saraiva, 2012 - (Coleção saberes do direito; 53)

BIANCHI, Angela Andrade; GARCEZ, José Maria Rossani; MAIA, Andrea. Origens e norteadores da mediação de conflitos. In: ALMEIDA, Tania; PELAJO, Samantha; JONATHAN, Eva (Coord.). Mediação de conflitos para iniciantes, praticantes e docentes. Salvador: JusPodivm, 2016.

BRASIL. Lei $\mathbf{n}^{\circ} \mathbf{1 3 . 1 0 5}$ de 16 de março de 2015. Dispõe sobre o Novo Código Civil. Disponível em: http://www.planalto.gov.br/ccivil_03/_Ato2015-2018/2015/Lei/L13105.html. Acesso em: julho 2017.

BRASIL. Lei $\mathbf{n}^{\circ} \mathbf{1 3 . 1 4 0}$ de 26 de junho de 2015. Dispõe a mediação entre particulares como meio de solução de controvérsias e sobre a autocomposição de conflitos no âmbito da administração pública; altera a Lei $n^{0} 9.469$, de 10 de julho de 1997 , e o Decreto $\mathrm{n}^{0} 70.235$, de 6 de março de 1972; e revoga o $\S 2^{\circ}$ do art. $6^{\circ}$ da Lei $n^{0} 9.469$, de 10 de julho de 1997. Disponível em: http://www.planalto.gov.br/ccivil_03/_Ato2015-2018/2015/Lei/L13140.html. Acesso em: julho 2017.

BRASIL. Resolução no 125, de 29 de novembro de 2010. Dispõe sobre a Política Judiciária Nacional de Tratamento adequado dos conflitos de interesses no âmbito do Poder Judiciário e dá outras providências. Disponível em: http://www.cnj.jus.br/busca-atosadm?documento=2579. Acesso em: julho2017.

CAMPILONGO, Celso Fernandes. Acesso à Justiça e formas alternativas de resolução de conflitos: serviços legais em São Bernardo do Campo. Revista Forense, n. 318. Rio de Janeiro: Forense, 2000.

CAPPELlETTI, Mauro; GARTH, Bryant. Acesso à justiça. Porto Alegre: Sérgio Antonio Fabris, 1988.

CINTRA, Antônio de Araújo; GRINOVER, Ada Pellegrini; DINAMARCO, Cândido Rangel. Teoria geral do processo. $31^{\mathrm{a}}$. ed. São Paulo: Malheiros, 2015. 
DAN, Wei. Mediação na China: passado, presente e futuro. In: CASELLA, Paulo Borba; SOUZA, Luciane Moessa (coord.). Mediação de conflitos: novos paradigmas de acesso à justiça. Belo Horizonte: Fórum, 2009.

DAVIS, Edwards p. MEDIAÇÃO NO DIREITO COMPARADO. 2017. http://www.cjf.jus.br/revista/seriecadernos/vol22/artigo02.pdf $+\& c d=4 \& h l=p t-$

$\underline{\mathrm{R} \& \mathrm{ct}=\mathrm{clnk} \& \mathrm{gl}=\mathrm{br}}$, Acessado em 22de julho de 2017.

GOMES NETO, José Mário Wanderley. O acesso à justiça em Mauro Cappelletti: análise teórica desta concepção como "movimento" de transformação das estruturas do processo civil brasileiro. Porto Alegre: Sergio Antonio Fabris Editor, 2005.

GORETTI, Ricardo. Acesso à Justiça e Mediação: ponderações sobre os obstáculos à efetivação de uma via alternativa de solução de conflitos. Disponível em: WWw.dominiopublico.gov.br/download/teste/arqs/cp075887.pdf. Acesso em: 20/07/2017

GORETTI, Ricardo. Mediação e Acesso à Justiça / Ricardo Goretti - Salvador: Editora JusPodivm, 2016.

JÚNIOR, Aldemar de Miranda Motta; VASCONCELOS, Carlos Eduardo de,ORLANDO, Diego Faleck; Fabíola; NETO, Francisco Maia; DORNELLES, Ricardo; PELAJO, Samantha. Manual de resolução de conflitos para advogados - escrito por advogados. - [et al.]. - 3 . Ed. - Brasília: Ministério da Justiça ; ENAM, Escola Nacional de Mediação e Conciliação, 2014.

KOURY, Luiz Ronan Neves. Mediação e conciliação no novo Código de processo civil: seus desdobramentos no direito processual do trabalho. Revista eletrônica [do] Tribunal Regional do Trabalho da 9a Região, Curitiba, PR, v. 5, n. 53, p. 35-45, ago. 2016.

MENDES, Aluísio Gonçalves de Castro; HARTMANN, Guilherme Kronemberg. A audiência de conciliação ou de mediação no novo Código de Processo Civil. Revista de Processo, São Paulo, v. 41, n. 253, p. 163-184, mar. 2016.

REICHELT, Luis Alberto. A exigência da publicidade dos atos processuais na perspectiva do direito ao processo justo. Revista de Processo | vol. 234/2014 | p. 77 | Jun. / 2017.

RIBEIRO, Darci Guimarães, JOBIM, Marco Félix. (organizadores); Desvendando o Novo CPC. Alexandre Freitas Câmara ... [et al.]. 3. Ed. ampl. - Porto Alegre: Livraria do Advogado Editora, 2017.

ROSENBLATT, Ana (organizador). Manual de mediação e conciliação para a Defensoria Pública. - [et al.]. - 3. Ed. - Brasília: Ministério da Justiça, 2015.

SCAVONE, Luiz Antonio. Manual de arbitragem: mediação e conciliação / Luiz Antonio Scavone Júnior. - 7. Ed. ver., atuali. e ampl. - Rio de Janeiro: Forense, 2016.

SERPA, M. de N. Teoria e prática da mediação de conflitos. Rio de Janeiro: Lúmen Júris. 1999 
SOUZA, Cláudia Maria Gomes de, SCHMIDT, Martha Halfeld Furtado de Mendonça, PEREIRA, Rita Andréa Guimarães de Carvalho, e JAYME, Fernando (Coord.), MEDIAÇÃO DE CONFLITOS: a emergência deum novo paradigma. /. Belo Horizonte: Del Rey, 2016.

SPENGLER, Fabiana Marion. Mediação de conflitos: da teoria à prática / Fabiana Marion Spengler. 2. ed. rev. e ampl. - Porto Alegre: Livraria do Advogado, 2017.

TARTUCE, Fernanda. Mediação de Conflitos Civis. 3. Ed., rev., atual. e ampl. - Rio de Janeiro: Forense; São Paulo: MÉTODO: 2016.

URY. William; Brett, Jeanne; Goldenberg, Stephen. Resolução de Conflitos. Lisboa. Actual editora. 2009

VARGAS, Lúcia Fátima Barreira Dias. Julgados de Paz e Mediação: uma nova face da Justiça. Coimbra: Almedina, 2006, p. 81.

VASCONCELOS, Carlos Eduardo de. Mediação de conflitos e práticas restaurativas / Carlos Eduardo de Vasconcelos, - 4. ${ }^{\mathrm{a}}$ ed. rev., atual. e ampl. - Rio de Janeiro: Forense; São Paulo: MÉTODO, 2015.

WATANABE, Kazuo. Política Pública do Poder Judiciário Nacional para ratamento Adequado dos Conflitos de Interesses. In: RICHA, Morgana de Almeida; PELUSO, Antonio Cezar. (Coord.). Conciliação e mediação: estruturação da política judiciária nacional. Rio de Janeiro: Forense, 2011.

ZANETI JR., Hermes. TRÍCIA, Navarro Xavier Cabral. Justiça Multiportas: mediação, conciliação e arbitragem e outros meios de solução adequada para conflitos. Salvador: Jusdopivm, 2016. 